\title{
Das Dificuldades da Química Verde a0s SEgundos Doze PrincíPIOS
}

AdÉlIo A. S. C. Machado

Apresenta-se uma revisão bibliográfica de exemplos recentes de reaç̧ões e compostos propostos como sendo resultado de Química Verde (QV) porque cumprem isoladamente um Princípio da QV, mas que em segunda análise se verificou que o não eram, porque atingiam desfavoravelmente outros. Sugere-se uma alteração de postura dos químicos laboratoriais para evitar a repetição de tais situações: a investigação de reacções, compostos e processos verdes deve ser procurada por via sistémica - ser dirigida ao objectivo primordial de obter verdura e aferida por aplicação simultânea e global de todos os Doze Princípios. Para ajudar a concretizar esta mudança de atitude é vantajoso aplicar os Segundos Doze Princípios da QV, formulados por Winterton, cuja utilidade e alcance são brevemente analisados.

No passado recente, têm sido publicitados na literatura científica da Química Verde (QV) novos compostos, reacções químicas, processos de realizar sínteses de compostos, etc., como sendo verdes - mas que, em segunda análise, se verifica que, embora envolvam melhorias quanto a certos aspectos da química usada (ambientais, de segurança, etc.), ignoraram outros, mantendo-os ou piorando-os. Estas situações afectam a reputação da QV e são prejudiciais para o seu desenvolvimento, sendo desejável prevenir a sua ocorrência.

A meta final deste artigo é contribuir para esta acção preventiva, para o que se cumprirão três objectivos específicos. Primeiro, discutir brevemente exemplos que foram apresentados como sendo de QV mas que uma escrutinação mais profunda revelou que nem sempre o eram. Segundo, apresentar sugestões quanto à atitude que os químicos devem adoptar com vista a minimizar falsas reivindicações de QV. Terceiro, chamar a atenção para os chamados Segundos Doze Princípios da $Q V$, formulados por Winterton em 2001 [1], cuja utilização pode ser muito útil para ajudar a cumprir o objectivo anterior. Este conjunto de Princípios tem sido muito menos publicitado do que os Doze Princípios de Anastas e Warner [2], já divulgados previamente neste boletim [3], mas deve merecer igualmente interesse por parte dos químicos, dada a sua utilidade para suportar a prática da QV de modo LAQUIPAI, Departamento de Química da Faculdade de amachado@fc.up.pt adequado a ser transferida suavemente do laboratório para a indústria.

\section{Casos de "falsa Química Verde"}

Começa-se por apresentar alguns exemplos de situações em que a prossecução de alguns dos Princípios da QV conduziu a um apregoado acréscimo de verdura - mas apenas aparente, porque as soluções adoptadas, embora propondo-se resolver alguns problemas, acabaram inadvertidamente por criar outros. ${ }^{1}$ Os casos envolvem escalas de actuação muito diferentes, o que evidencia o largo alcance desta questão - tão lato como o da própria Química.

\section{Exemplo 1 - Reacções}

Têm sido propostas como verdes certas reacções de síntese orgânica catalisadas por pequenas moléculas orgânicas em presença de água, que permitem obter velocidades de reacção mais elevadas e enantioselectividade aumentada ( $p$. ex., para certas reacções aldol' ${ }^{2}$ [4-6]. O uso da água como solvente cumpre o Princípio 5 da QV (privilegiar solventes benignos) e o uso de catalisadores orgânicos segue o Princípio 9 (preferir reacções catalíticas). No entanto, tais reacções podem dar origem a resíduos constituídos por misturas complexas de água e solventes orgânicos, provenientes do meio reaccional e também dos tratamentos para acabamento do produto. A separação dos solventes orgânicos nestas misturas é proibitivamente complexa, pelo que, na prática, não pode ser feita a sua recuperação; por outro lado, as misturas são difíceis de incinerar devido à presença da água [4]. Em suma, o que aparentemente se ganha em verdura na reacção, afinal perde-se quando se cria com os resíduos um problema ambiental de resolução difícil.

\section{Exemplo 2 - Os líquidos iónicos como solventes}

Os líquidos iónicos ${ }^{3}$ têm sido frequentemente apresentados como solventes verdes que podem substituir com vantagens os solventes orgânicos tradicionais (Princípio 5 da QV). A sua proposta como solventes verdes tem como base os factos seguintes:

- a tensão de vapor dos líquidos iónicos seria praticamente nula, presumivelmente impossível de medir, pelo que a sua volatilização e dispersão no ambiente seriam limitadas (em particular, a exposição por inalação dos trabalhadores que os manejam seria menor do que para solventes orgânicos tradicionais);

- presunção de serem termicamente estáveis até temperaturas relativamente elevadas e não serem inflamáveis, pelo que os riscos de acidente (incêndio e, eventualmente, explosão), quando se perde o controlo na realização de reacções exotérmicas (polimerizações, oxidações, etc.), seriam limitados; além disso, a estabilidade potenciaria a reutilização;

- presunção de serem relativamente não tóxicos, pelo que os seus efeitos no ambiente seriam nulos ou quase inócuos. 
No entanto, quando recentemente se começaram a escrutinar as propriedades dos líquidos iónicos, estas ideias foram postas em causa. Quanto a (i), é possível medir a pressão de vapor e a entalpia de vaporização de líquidos iónicos e verificou-se que alguns deles podem ser destilados [7,8], 0 que mostra que a presunção de involatilidade quase absoluta é incorrecta. Por outro lado, quanto a (ii), testes de combustibilidade revelaram que certos líquidos iónicos, quando aquecidos, sofrem ignificação [9]; e testes de termogravimetria mostraram que certos compostos deste tipo se degradam termicamente $[10,11]$. Finalmente, a realização de ensaios de citotoxicidade, toxicidade e ecotoxicidade, mostrou já que certos líquidos iónicos apresentam actividade biológica deletéria; além disso, ensaios de degradação ambiental mostraram que a extensão da biodegradabilidade pode variar bastante de composto para composto - um artigo de revisão recente proporciona um panorama do trabalho realizado neste campo [12]. Note-se que o estudo das propriedades tóxicas destes compostos é bastante complexo porque eles envolvem duas espécies, o anião e o catião, e se um deles for tóxico, é de presumir que o líquido iónico também o seja - é o que sucede, por exemplo, nos casos do catião ser baseado no grupo imidazólio ou do anião ser uma espécie fluorada.

Estes factos mostram que, como para quaisquer outros compostos, não é de admitir a utilização de líquidos iónicos em Química Industrial sem avaliação prévia e cabal das propriedades dos compostos a usar, em especial as de toxicidade e as que afectam o destino ambiental. Em face destes problemas, no actual contexto de promulgação de legislação ambiental cada vez mais limitativa (por exemplo, o $\mathrm{REACH}^{4}$ ), as empresas industriais serão desmotivadas a considerar a utilização de líquidos iónicos como solventes nos seus processos de fabrico. O seu licenciamento para aplicação em larga escala terá de ser considerado caso a caso, sendo de prever que sejam impostas restrições à sua utilização em muitos casos, que complicam o manejamento - só quando a utilidade e eficácia de um líquido iónico em síntese ou outra aplicação se traduzir em vantagens económicas que justifiquem o seu uso condicionado é que as empresas os adoptarão para inovar processos. Esta situação é bastante diferente da propagandeada por muitos dos investigadores entusiastas no campo dos solventes iónicos desde a emersão da QV.

Claro que o facto de os líquidos iónicos não serem inerentemente verdes, não implica que deixem de ser considerados para aplicação industrial: apenas significa que é necessário procurar proactivamente a benignidade quando se desenham compostos deste tipo para cumprir funções no mundo real, tal como para quaisquer outros compostos - o que limitará o número de compostos susceptíveis de aplicação. Esta postura já foi adoptada por um número restrito de investigadores no campo, que incluíram intencionalmente objectivos de benignidade no design de líquidos iónicos [13-15]. Paralelamente, está a ser intensificada a investigação das propriedades tóxicas e consequentes riscos deste tipo de compostos (p. ex. [16-17]).

Finalmente, em contraponto especialmente dedicado às mentes renitentes a aceitar que é necessário considerar a perigosidade dos líquidos iónicos antes de se passar à sua utilização, refira-se que também neste campo se pode perseguir proactivamente a "malignidade": é possível preparar líquidos iónicos intencionalmente perigosos - por exemplo, têm vindo a ser estudados consistentemente compostos deste tipo com grupos energéticos que poderão vir a ter utilidade prática como explosivos e propelantes [18-21]. Estas aplicações exigirão obviamente precauções limitativas na utilização, para garantir que só são usados por "boas mãos", para fins específicos e benéficos. Se por acaso caírem em "más mãos", será mais um exemplo da natureza dual da ciência em geral e da química em particular tanto pode servir o bem como o mal, tudo depende do modo como é utilizada.

\section{Exemplo 3 - Uso de microondas para aquecimento}

A utilização laboratorial em síntese orgânica de equipamento de micro- ondas em substituição de mantas de aquecimento e de banhos de óleo tem sido apresentada como sendo uma medida que suporta a $\mathrm{QV}$, nomeadamente quanto ao Princípio 6 (aumento da eficiência energética) [22-24]. Desde a sua introdução, em meados dos anos oitenta do século $X X$, esta modalidade de aquecimento tem vindo a ganhar bastante aceitação para realizar variados tipos de reacções de síntese em Química Orgânica, particularmente a partir da introdução de equipamento dedicado a uso laboratorial, em meados dos anos noventa [25-28]. Em casos felizes, a técnica permite obter velocidade de aquecimento elevada, reduzir o tempo de reacção (de horas para minutos), usar condições de reacção mais brandas, reduzir a extensão de reacções laterais e aumentar o rendimento da reacção e sua reprodutibilidade - porque proporciona um aquecimento eficiente em toda a massa reaccional por fricção molecular (e não de fora para dentro, como no caso do aquecimento clássico por transferência de calor por condução-convexão). Duas áreas onde o uso de microondas permitiu obter sínteses laboratoriais inovadoras foram a das reacções sem solvente e a das reacções realizadas em solventes de baixo ponto de ebulição (álcoois etílico e metílico, acetato de etilo, etc.) ou na própria água, em recipiente fechado - onde o aquecimento por microondas permite obter temperaturas muito superiores à do ponto de ebulição em pouco tempo, sendo o sobreaquecimento do solvente possível devido ao aumento autogénico de pressão. ${ }^{5}$

Não obstante a divulgação do uso de microondas para aquecimento, são raros na literatura os estudos em que se procurou determinar experimentalmente os ganhos de energia conseguidos comparativamente com os aquecimentos clássicos, uma das razões porque foram propalados como suportando a QV. Um primeiro trabaIho sobre este assunto [29], de natureza preliminar e que contemplou apenas três reacções, revelou que nem sempre ocorria poupança de energia consumida e que, quando ocorria, a sua extensão era muito variável de caso para caso (para uma reacção de acoplamento de Suzuki atingiu 
85 vezes, noutros casos foi bastante menor). Um outro estudo [30], sobre a transesterificação de ácidos gordos para produzir biodiesel, em que a reacção foi realizada em reactor laboratorial aberto, não mostrou grandes ganhos de energia quando foi usado o aquecimento por microondas $(90,1$ $\mathrm{kJ} / \mathrm{L}$ de biodiesel) relativamente ao convencional (94,3 kJ/L, calculado).

Finalmente, um estudo mais recente e detalhado [31], com o objectivo expresso de investigar as vantagens e desvantagens do aquecimento por microondas, comparou quatro reacções, realizadas em diferentes condições.

Os seus resultados foram esclarecedores.

Para a reacção de hidrólise da benzamida com ácido sulfúrico (ver Tabela 1): no caso de refluxo em recipiente aberto, o aquecimento por microondas consome significativamente mais energia do que as técnicas de aquecimento clássico (manta eléctrica ou banho de óleo, comparar experiências 8 e 9 com 2 e 3 na tabela), o que se deve em grande parte à baixa eficiência do magnetrão na conversão de energia eléctrica em microondas (da ordem de 50-65\%); pelo contrário, quando o aquecimento é realizado em recipiente fechado (selado), atingem-se temperaturas elevadas em pouco tempo e ocorre o sobreaquecimento do solvente (possível devido ao aumento autogénico de pressão), o uso de microondas permite uma poupança significativa de energia - devida, sobretudo, ao encurtamento do tempo de reacção requerido, já que a temperaturas elevadas as velocidades de reacção são maiores (experiências 5, 6 e 7 na tabela).

A comparação de experiências envolvendo outras reacções mostrou que os consumos de energia no aquecimento por microondas dependem da natureza do solvente, mais precisamente, do seu momento dipolar, que afecta as características de absorção da radiação pela mistura de reacção, e do seu ponto de ebulição, bem como da escala de operações - à escala laboratorial (5-200 $\mathrm{mmol}$ de reagentes num volume de 4-300 $\mathrm{ml}$ ) [31].

Tabela 1 Consumo energético da hidrólise da benzamida com $\mathrm{H}_{2} \mathrm{SO}_{4} 5 \%$ a,b

\begin{tabular}{|c|c|c|c|c|c|}
\hline Exp & $\begin{array}{c}\text { Método de } \\
\text { aquecimento }\end{array}$ & Escalad $^{\text {d }}$ & $\begin{array}{c}\text { Temperatura de } \\
\text { reacção (ㄷ) }\end{array}$ & $\begin{array}{c}\text { Tempo } \\
(\mathrm{min})\end{array}$ & $\begin{array}{c}\text { Consumo } \\
(\mathrm{kW} . \mathrm{h} / \mathrm{mol})\end{array}$ \\
\hline \multicolumn{7}{|c|}{ Aquecimento clássico } \\
\hline 1 & Banho de óleo & $1 / 10$ & 100 & 720 & 80,10 \\
\hline 2 & Banho de óleo & $5 / 50$ & 100 & 720 & 18,26 \\
\hline 3 & Manta eléctrica & $5 / 50$ & 100 & 720 & 19,24 \\
\hline 4 & Autoclave & $0,4 / 4$ & 180 & 7 & 31,30 \\
\hline \multicolumn{7}{|c|}{ Aquecimento por microondas } \\
\hline 5 & Selado (A) & $0,4 / 4$ & 180 & 7 & 1,36 \\
\hline 6 & Selado (B) & $0,4 / 4$ & 180 & 7 & 8,38 \\
\hline 7 & Selado (A) & $1 / 10$ & 180 & 7 & 1,20 \\
\hline 8 & Selado (B) & $5 / 50$ & 100 & 120 & 48,23 \\
\hline 9 & Selado (C) & $5 / 50$ & 100 & 120 & 161,44 \\
\hline
\end{tabular}

a) Tabela simplificada de [31]

b) Reacção:

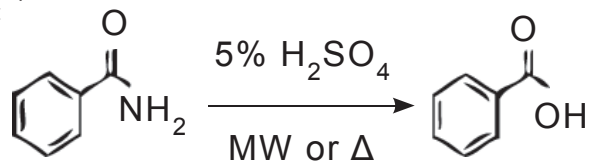

c) A, B e C referem-se a diferentes tipos de equipamento de microondas de laboratório d) Massa de benzamida (g)/Volume de $\mathrm{H}_{2} \mathrm{SO}_{4}(\mathrm{ml})$

Os artigos laudatórios do aquecimento por microondas também esquecem frequentemente as limitações da técnica, que têm de ser tidas em conta para avaliar a sua potencialidade para proporcionar verdura à química. Desde logo, o aquecimento por microondas pode não ser exequível, por exemplo, se a reacção requerer um solvente apolar, cuja absorção das microondas é limitada, a não ser que os reagentes, catalisadores, etc., sejam polares e proporcionem absorção, ou se possa usar um agente passivo, fortemente absorvente, que provoque o aquecimento (por exemplo, uma vareta de carboneto de silício, $\mathrm{SiC}$, inserida no reactor). Por outro lado, não se pode esquecer que o tratamento preliminar dos reagentes e a purificação do produto ("work-up") consomem frequentemente quantidades de energia que não podem ser desprezadas face à energia gasta na reacção. Este aspecto não foi incluído em nenhum dos estudos anteriormente referidos, mas tem de ser considerado quando se pretende avaliar o ecobalanço energético global do processo.

Finalmente, será de registar que o escalamento do aquecimento por microondas para a grande escala industrial é problemático - nunca foi feito e o escalamento directo é provavelmente impossível de realizar, devido à profundidade de penetração das microondas em meios absorventes ser limitada ${ }^{6}$ (a questão da segurança levantaria também problemas). Até ao momento, o escalamento foi realizado apenas à escala laboratorial, da ordem de alguns gramas para centenas de gramas ou, em reactores de fluxo, para a escala intermédia de alguns quilogramas, mas estes últimos reactores não permitem a realização de reacções sem solvente [32,33]; por outro lado, os reactores de fluxo são naturalmente abertos, pelo que também não possibilitam aquecimento em vaso selado - em conclusão, o escalamento de situações em que o uso de microondas teve êxito no laboratório parece problemático. O escalamento para quantidades maiores (instalação piloto ou industrial) só poderá ser realizado por replicação de reactores ("numbering-up"), provavelmente de fluxo contínuo $[27,28]$.

Em suma, o aquecimento por microondas não possibilita sempre um aumento de verdura energética relativamente aos aquecimentos convencionais - a situação tem de ser avaliada caso a caso. Embora o uso de microondas no laboratório, em casos felizes, ajude a promover a QV a esta escala, à escala real da Química Industrial será mais difícil a obtenção de proveitos generalizados de verdura por esta via. 


\section{Exemplo 4 - Os biocombustíveis}

Recentemente, tem havido um grande interesse em pressionar o fabrico de biocombustíveis - bioetanol, biodiesel, etc. - a partir de matérias-primas de origem vegetal, portanto renováveis (Princípio 7 da QV), sem se atender aos variados efeitos nocivos sobre o ambiente que as práticas agrícolas para obtenção de biomassa e que a conversão industrial desta em biocombustíveis podem exercer [34], bem como à energia dispendida na produção agrícola. Esta última compreende variadas parcelas, nem sempre integralmente contabilizadas: - gasóleo usado no equipamento agrícola, a energia usada no fabrico de fertilizantes e produtos fitossanitários e respectivos transportes, electricidade e gás gastos nas instalações agrícolas, etc.

A energia produzida pelo biocombustível tem de ser superior à investida na sua produção para que esta valha a pena do ponto de vista energético e ambiental. Este aspecto é avaliado mediante balanços energéticos detalhados, que permitem calcular a eficiência energética da produção em geral, esta é avaliada pela razão "energia obtida para energia investida" (EROI). ${ }^{7}$

Por exemplo, balanços energéticos detalhados, realizados num estudo comparativo recente (2005), mostraram que o fabrico de bioetanol a partir da cana-de-açúcar (Brasil) apresenta um valor do EROI muito superior ao do bioetanol obtido a partir dos grãos de milho (EUA) [35].

A Tabela 2 apresenta valores obtidos no balanço energético do bioetanol produzido nos dois países, que permitem concluir que o bioetanol de cana tem um EROI com valor apreciável $(3,67)$, ao passo que o de milho tem um valor marginal $(1,10)$ - pelo que, em termos energéticos, a produção do primeiro é proveitosa, ao passo que a do segundo é problemática.

O estudo compreendeu também o cálculo da pegada ecológica ${ }^{8}$ do biocombustível nos dois países, obtida como a soma da área de solo agrícola para cultivar a matéria-prima vegetal

(cana ou milho) e da área de floresta necessária para absorver o dióxido de carbono emitido na produção, distribuição e combustão do bioetanol ou na distribuição e combustão da gasolina com que aquele é misturado.

Os valores apresentados na Tabela 2 mostram que a pegada ecológica do bioetanol de cana usado no Brasil é cerca de metade da gasolina $\mathrm{E} 85^{9}$ usada nos EUA.

Tabela 2 Balanço de energia da produção de bioetanol (GJ/hectare) e Pegada Ecológica - comparação do bietanol de cana (Brasil) e de milho (EUA) a,b

\begin{tabular}{|c|c|c|c|c|}
\hline $\begin{array}{c}\text { Sector da } \\
\text { produção }\end{array}$ & $\begin{array}{c}\text { Energia } \\
\text { investida }\end{array}$ & $\begin{array}{c}\text { Energia } \\
\text { obtida }\end{array}$ & EROIc & $\begin{array}{c}\text { Pegada } \\
\text { ecológica (ha) }\end{array}$ \\
\hline \multicolumn{6}{|c|}{ Cana do açúcar (Brasil) } \\
\hline Agricultura & 35,98 & - & & \\
\hline Indústria & 3,63 & 155,57 & & \\
\hline Distribuição & 2,82 & - & & $0,56^{d}$ \\
\hline Total & 42,43 & 155,57 & 3,67 & \\
\hline \multicolumn{6}{|c|}{ Grão de milho (EUA) } \\
\hline Agricultura & 22,08 & - & & \\
\hline Indústria & 41,60 & 71,44 & $1,11 \mathrm{e}$ \\
\hline Distribuição & 1,34 & - & 1,10 & \\
\hline Total & 65,02 & 71,44 & 10 & \\
\hline
\end{tabular}

a) Tabela adaptada de [35]

b) Valores referentes a um automóvel usado durante um ano, expressos em ha

c) Razão "energia obtida para energia investida" (ver nota ${ }^{7}$ )

d) Para automóveis a gasool (mistura de $76 \%$ gasolina $+24 \%$ etanol) o valor é 0,63

e) Este valor refere-se a gasolina E85 (85\% de gasolina + 15\% etanol); para veículos a gasolina pura, o valor é 1,74 .

Este exemplo mostra quão complexa é a verdura dos biocombustíveis - que, apesar de serem "bio", podem ser, ou não, tão verdes como se propala.

O problema da verdura dos biocombustíveis é muito elaborado e não se ousa tratá-lo aqui em pormenor, mas vinca-se que sem Agricultura Verde não pode haver biocombustíveis verdes e que a Agricultura Verde é algo ainda mais difícil de praticar do que a QV. ${ }^{10}$

\section{Dıscussão}

Os exemplos considerados mostram que um aumento de verdura num dado aspecto de um composto ou reacção, resultante da aplicação proactiva feliz só de um ou alguns dos Princípios da QV, não significa necessariamente que o composto ou processo de o sin- vo final de obter verdura global - e escrutinando simultaneamente todos os Princípios da $Q V$, etapas do ciclo de vida do composto e/ou reacção, etc., e a todas as suas implicações para a perseguição da verdura.

Os químicos académicos ou laboratoriais, formados num enquadramento mental reducionista, oferecem frequentemente resistência à mudança para uma postura sistémica, devido a razões variadas, exemplificadas tentativamente e sem preocupações de exaustividade no Quadro 1.

Estas razões incluem desde a formatação mental embutida pelo ensino da ciência em moldes tradicionais, que resiste a visões integradas, até deficiências de formação em campos relevantes para a QV que não fazem parte da química. 
Quadro 1 Limitações à adopção holística da Química Verde pelos Químicos Académicos

\section{Formação reducionista}

dificuldade em realizar abordagens holísticas (p. ex., ciclo de vida) e em usar conjugada e integradamente os Doze Princípios

Formação limitada em: toxicologia/ecotoxicologia

destino ambiental dos produtos químicos

(mecanismos de transporte, reacções em trânsito, etc.)

prática da Química Industrial (incluindo a sua componente económica) Sustentabilidade

Mentalidade quantitativa limitada ("resistência" ao uso de métricas quantitativas)

\section{3-Identificar equantificar os coprodutos(subprodutos eventuais e resíduos)} Identificar os coprodutos e determinar as suas quantidades relativamente à do produto principal

14 - Obter conversões, selectividades, produtividades, etc.

Para além do rendimento químico das reacções de síntese, determinar métricas relevantes para a QV: selectividades, produtividades (eficiência atómica e similares), etc.

15 - Estabelecer balanços materiais completos para o processo Especificar, quantificar e contabilizar todos os materiais usados na obtenção do produto final, incluindo os auxiliares, nomeadamente os solventes

16 - Determinar as perdas de catalisadores e solventes nos efluentes Determinar as quantidades ou caudais dos fluxos de efluentes líquidos, sólidos, e gasosos e as concentrações de reagentes auxiliares neles

\section{7 - Investigar a termoquímica básica do processo}

Avaliar e relatar as variações de entalpia das reacções exotérmicas para alertar sobre eventuais problemas de libertação de calor com a mudança de escala

\section{8 - Considerar limitações de transferência de calor e de massa}

Identificar factores que afectem a transferência de calor e de massa no escalamento (velocidade de agitação ou de dispersão de gases, área de contacto gás-líquido, etc.) 19 - Visualizar as reacções sob a perspectiva dos engenheiros químicos Identificar e compreender pontos de constrição para o escalamento da química no desenvolvimento do processo industrial por estudo das várias alternativas de tecnologia disponíveis para o implementar e contactos com engenheiros químicos

\section{0 - Considerar a globalidade do processo industrial} ao seleccionar a química de base

Avaliar o impacto das alternativas possíveis de todas as variáveis de processo (matérias-primas, natureza do reactor, operações de separação, etc.) nas opções possíveis para a química de base

Realizar experiências com os reagentes comerciais que vão ser utilizados no fabrico

21 - Ajudar a desenvolver e aplicar medidas de sustentabilidade do processo

Avaliar quantitativamente, na extensão possível, o grau de sustentabilidade do processo industrial (actividade ainda incipiente, mas com futuro)

\section{2 - Quantificar e minimizar o uso de "utilidades"}

Dar atenção ao uso e minimização das "utilidades" e proporcionar informação que permita avaliar as respectivas necessidades logo no início do desenvolvimento do processo e ao longo do escalamento da síntese

\section{3 - Identificar situações de incompatibilidade entre a segurança do} processo e a minimização de resíduos

Dar atenção à segurança do processo a desenvolver com base na síntese laboratorial e alertar para o facto de existirem restrições de segurança que limitam as condições de implementação da reacção à escala industrial

24 - Monitorizar, registar e minimizar os resíduos produzidos na realização laboratorial da síntese

Dar atenção pormenorizada e quantitativa aos resíduos produzidos na síntese laboratorial e lutar pela sua minimização

(*) Estes Princípios [1] foram numerados a partir de treze para impedir confusões com os Doze (Primeiros) Princípios da QV (de Anastas e Warner [2]) listados em [3]

\section{Os Segundos Doze Princípios DA QV}

A mudança de atitude pode ser facilitada se os químicos interiorizarem os chamados Segundos Doze Princípios da QV, formulados por Winterton (2001) e que são dirigidos especialmente aos profissionais da Química Académica que divisam novos processos de síntese de moléculas [1]. Estes princípios, que suplementam os Doze Princípios "clássicos," são apresentados brevemente no Quadro 2, numerados a partir de treze (na sequência dos primeiros doze [3] e para evitar confusões com estes), e podem contribuir para a adopção de uma mentalidade mais pragmática quanto à concretização de QV e, especialmente, facilitar as tarefas posteriores de desenvolvimento do processo de fabrico verde, tornando-o mais expedito e eficaz.

Os Segundos Doze Princípios apelam aos químicos académicos que realizam a investigação de laboratório sobre síntese de compostos químicos para incluir na sua actividade uma atitude proactiva de atenção às características de verdura (ou sua falta) das reacções químicas que desenvolverem ou usarem - o que exige que foquem mais atenção na verdura. Tal atitude passa por: (i) planeamento e realização de trabalho laboratorial de base globalmente mais dirigido para a QV; e (ii) colheita e publicação de informações relativas à verdura das reacções químicas que utilizarem nas sínteses que inventarem. Neste contexto, os Segundos Doze Princípios pressionam os químicos laboratoriais para que privilegiem, em particular, respectivamente: (i) o estudo da química básica necessária para obter vias de síntese mais verdes; e (ii) a colecta de dados adicionais que permitam avaliar comparativamente as características de verdura das novas vias de síntese investigadas e estabelecidas (ver nomeadamente os Princípios 15, 16 e 21) - mediante cálculo de métricas de massa e ambientais [36].

Assim, a adopção destes princípios suplementares, embora requeira trabalho adicional, poderá contribuir decisivamente para a consolidação do Design Verde de produtos e processos, porque a disponibilização da informação recolhida facilitará a ava- 
liação do potencial das reacções químicas estudadas no laboratório para serem escaladas com boas soluções técnicas e sem perda das suas características verdes. Esta informação permitirá aos engenheiros químicos e químicos de processo obter com mais facilidade, por exemplo, bons níveis de minimização de resíduos e de consumo de energia, quando as mesmas reacções são realizadas a escala maior do que no laboratório (à escala piloto ou de processo).

A disponibilidade de dados deste tipo é importante porque a verdura de uma reacção química só tem interesse real no contexto da sua utilização na prática industrial, que é sempre precedida pelo estudo do respectivo escalamento. Embora a obtenção da verdura à escala industrial envolva frequentemente compromissos entre factores contraditórios, impostos por considerações técnicas, económicas ou comerciais (e não apenas químicas), a adopção dos novos princípios pelos investigadores laboratoriais facilitará a avaliação e comparação da verdura potencial das diversas alternativas de processos químicos, logo desde as primeiras actividades do desenvolvimento do processo - incluindo a fase preliminar de selecção do próprio produto.

\section{Conclusão}

Em suma, o desenvolvimento da QV exige que os químicos laboratoriais de síntese passem a pensar e actuar estrategicamente, com alcance global, de modo sistémico, dirigido ao objectivo de obter verdura total - para o que têm de considerar sempre simultanea e integradamente, como um "sistema coesivo" [37], todos os Doze Princípios da QV (e não só). A interiorização dos Segundos Dozes Princípios, que obrigam a escrutinar explicitamente as características de verdura, ou pelo menos uma parte destas, poderá constituir uma ajuda para a adopção desta postura holística.

A aplicação dos Segundos Doze Princípios da QV pelos químicos laboratoriais, só por si, não garante o desenvolvimento posterior, à escala industrial, de processos quími- cos limpos. No entanto, eles ajudarão aqueles químicos a fazer incidir a sua atenção nas áreas de investigação mais produtivas quanto à QV e a seleccioná-las precocemente como merecedoras de actividade prioritária - isto é, favorecem uma atitude proactiva dos químicos com respeito à $\mathrm{QV}$. Além disso, o seu seguimento pode proporcionar muita informação útil aos químicos e engenheiros químicos que procedem à selecção de produtos (isto é, dos compostos a fabricar) e se ocupam do desenvolvimento dos processos industriais para a sua fabricação - para eles poderem praticar mais facilmente o desenvolvimento do produto e processo de modo a obter características mais verdes.

\section{Notas}

1 Esta situação - ao resolver um problema provocar inadvertidamente a emergência de outro - tem sido comum ao longo do desenvolvimento da civilização, e merece a atenção da heurística, a actividade de resolver problemas [38]. Tais problemas são designados em inglês por unintended ou unintentional problems, termo que se poderá traduzir por problemas não intencionais, à falta de melhor tradução.

${ }^{2}$ As reacções aldol permitem o estabelecimento de uma ligação C-C, sendo muito importantes em Química Orgânica. Envolvem duas moléculas com grupos carbonilo (aldeídos, cetonas e derivados), eventualmente com perda de uma molécula de água, que dão origem à formação de uma ligação C-C em que os dois carbonos constituem dois novos centros estereogénicos cujas configurações absolutas e relativas podem ser controladas - o que é muito útil na síntese de moléculas mais complexas com as mesmas ligações mas com estereoquímicas diferentes (por exemplo, moléculas usadas como produtos farmacêuticos).

${ }^{3}$ Os líquidos iónicos são compostos integralmente compostos por iões (sais) com ponto de fusão inferior a $373 \mathrm{~K}$ ou $100^{\circ} \mathrm{C}$ (ou, segundo outros autores, até $298 \mathrm{~K}$ ou $25^{\circ} \mathrm{C}$, aproximadamente a temperatura ambiente, um critério muito mais restritivo, que deixa de fora muitos dos incluídos na definição anterior). Como podem integrar catiões e aniões orgânicos muito diversificados, constituem uma família de compostos muito numerosa e a sua composição pode ser manejada intencionalmente para condicionar as suas propriedades como solventes.
${ }^{4}$ Regulamento relativo ao Registo, Avaliação, Autorização e Restrição de substâncias químicas (REACH - Registration, Evaluation, Authorisation and Restriction of Chemicals).

${ }^{5} \mathrm{~A}$ temperatura elevada $\left(>200^{\circ} \mathrm{C}\right)$, a água comporta-se como um solvente pseudoorgânico: a constante dieléctrica decresce substancialmente, o produto iónico aumenta cerca de três décadas e o poder de solvatação é análogo ao do metanol e etanol à temperatura ambiente, etc. $\mathrm{A}$ temperaturas elevadas, certas reacções catalisadas por ácidos ou bases ocorrem mais rapidamente e exigem menores concentrações de catalisador.

${ }^{6}$ É esta mesma razão que determina o tamanho limitado dos microondas domésticos para cozinha - permitem assar um frango, mas não há "tamanho super" para peru ou carneiro inteiro (para famílias numerosas)!

${ }^{7}$ EROI é a abreviatura do inglês "energy returned on investment" (usam-se também outras abreviaturas/designações alternativas, nomeadamente EROEI ou ERoEl, que abreviam "energy returned on energy invested"). Note-se que o conceito, que foi inventado por economistas para estudar a economia da extracção do petróleo, é genérico, aplicando-se a qualquer processo de extracção ou produção de energia. No caso da extracção do petróleo do subsolo, o valor varia de jazida para jazida - quanto maior for, mais lucrativa é a exploração. O EROI da extracção do petróleo tem vindo a decrescer: nos anos trinta do século passado era de 100:1 ou mais, mas presentemente, quando a extraç̧ão exige perfuração horizontal de jazidas já sem grande pujança, pode diminuir para valores inferiores a 20:1, porque o material extraído é predominantemente água (por exemplo, só com $10 \%$ de petróleo) e a separação requer uma quantidade enorme de energia [38].

${ }^{8}$ A pegada ecológica [40,41] é uma ferramenta de cálculo da carga ambiental provocada por uma população humana, actividade económica, etc. que tem por base dois conceitos - a sustentabilidade e a capacidade de suporte ("carrying capacity") do solo terrestre. Consiste em determinar a área de solo necessária para produzir os recursos naturais, matérias-primas, etc., e para depor e assimilar os resíduos e poluentes envolvidos na manutenção sustentável de uma população, actividade económica, etc. Quanto mais recursos esta exigir e mais 
resíduos produzir, maior é a respectiva carga ambiental e maior será a pegada ecológica.

${ }^{9}$ A sigla E85 designa a mistura de $85 \%$ de gasolina com $15 \%$ de etanol.

${ }^{10}$ Embora não se tenha plena consciência disso, a prática da agricultura tem vindo a alterar o ambiente desde a sua invenção na Revolução Neolítica [42].

\section{REFERÊNCIAS}

[1] N. Winterton, "Twelve More Green Chemistry Principles", Green Chem. 3 (2001) G73-5.

[2] P. T. Anastas e J. C. Warner, "Green Chemistry - Theory and Practice", Oxford University Press, Oxford, 1998.

[3] A. A. S. C. Machado, "Química e Desenvolvimento Sustentável - QV, QUIVES, QUISUS?", Química - Bol. S. P. Q. 95 (2004) 59-67.

[4] D. G. Blackmond, A. Armstrong, V. Coombe e A. Wells, "Water in Organocatalytic Processes: Debunking the Myths", Angew. Chem. Int. Ed. 46 (2007) 3798-800.

[5] W. Leitner, "Green Solvents for Processes - The Colour for Solvents", Green Chem. 9 (2007) 923.

[6] R. Van Noorden, "How Environmentally-friendly is Green Chemistry?", Chem. World 4(6) (2007) 14-5.

[7] Y. U. Paulechka, Dz. H. Zaitsau, G. J. Kabo e A. A. Strechan, "Vapour Pressure and Thermal Stability of Ionic Liquid 1-Butyl-3-methylimidazolium Bis(trifluoromethylsulfonyl)amide", Thermochim. Acta 439 (2005) 158-60.

[8] M. J. Earle, J. M. S. S. Esperança, M. A. Gilea, J. N. C. Lopes, L. P. N. Rebelo, J. W. Magee, K. R. Seddon e J. A. Widegren, "The Distillation and Volatility of Ionic Liquids", Nature 439 (2006) 831-4.

[9] M. Smiglak, W. M.Reichert, J. D. Holbrey, J. S.Wilkes, L. Sun, J. S. Trasher, K. Kirichenko, S. Singh, A. R. Katritzky e R. D. Rogers, "Combustible Ionic Liquids by Design: Is Laboratory Safety Another Ionic Liquid Myth?", Chem. Commun. (2006) 2554-6.

[10] K. J. Baranyai, G. B. Deacon, D. R. MacFarnale, J. M. Pringle e J. L. Scott, "Thermal Degradation of Ionic Liquids at Elevated Temperatures", Aust. J. Chem. 57 (2004) 145-7.

[11] T. J. Wooster, K. M. Johanson, K. J. Fraser, D. R. MacFarlane e J. L. Scott, "Thermal Degradation of Cyano Containing lonic Liquids", Green. Chem. 8 (2006) 691-6.
12] J. Ranke, S. Stolte, R. Stormann, J. Arning e B. Jastorff, "Design of Sustainable Chemical Products - The Example of Ionic Liquids", Chem. Rev. 107 (2007) 2183-206.

[13] N. Gathergood, P. J. Scammells e M.T.Garcia, "Biodegradable Ionic Liquids - III - The First Readily Biodegradable Ionic Liquids", Green. Chem. 8 (2006) 156-60 (e artigos anteriores da série).

[14] G. Tao. L. He, W. Liu, L. Xu, W. Xiong, T. Wang e Y. Kou, "Preparation, Characterization and Application of Amino Acid-based Green Ionic Liquids", Green. Chem. 8 (2006) 639-46.

[15] Y. Fukaya, Y. lizuka, K. Sekikawa e H. Ohno, "Bioionic Liquids: Room Temperature Ionic Liquids Composed Wholly of Biomaterials", Green Chem. 11 (2007) 1155-7

[16] B. Jastorff, R. Störmann, J. Ranke, K. Mölter, F. Stock, B. Oberheitmann, W. Hoffmann, J. Hoffmann, M. Nüchter, B. Ondruschka e J. Filser, "How Hazardous are Ionic Liquids? Structure-activity Relationships and Biological Testing as Important Elements for Sustainability Evaluation", Green Chem. 5 (2003) 136-42.

[17] D. Kralisch, A. Stark, S. Korrsten, G. Kreisel e B. Ondruschka, "Energetic, Environmental and Economic Balances: Spice up your Ionic Liquid Research Efficiency", Green Chem. 7 (2005) 301-9.

[18] G. Drake, T. Hawkins, A. Brand, L. Hall, M. Mckay, A. Vig e I. Ismail, "Energetic, Low-Melting Salts of Simple Heterocycles", Propellants, Explos., Pyrotech. 28 (2003) 174-80.

[19] H. Xue, Y. Gao, B. Twamley e J. M. Shreeve, "Energetic Azolium Azolate Salts", Inorg. Chem. 44 (2005) 5068-72.

[20] A. R. Katritzky, H. Yang, D. Zhang, K. Kirichenko, M. Smiglak, J. D. Holbrey, W. M. Reichert e R. D. Rogers, "Strategies Toward the Design of Energetic Ionic Liquids: Nitro- and Nitrile-substituted N,N'-Dialkylimidazolium Salts", New J. Chem. 30 (2006) 349-58.

[21] A. R. Katritzky, S. Singh, K. Kirichenko, M. Smiglak, J. D. Holbrey, W. M. Reichert, S. K. Spears e R. D. Rogers, "In Search of Ionic Liquids Incorporating Azolate Anions", Chem. Eur. J. 12 (2006) 4630-41.

[22] C. R. Strauss e R. S. Varma, "Microwavess in Green and Sustainable Chemistry", Top. Curr. Chem 266 (2006) 199-231.
[23] B. A. Roberts e C. R. Strauss, "Toward Rapid, "Green" Predictable Microwave-Assisted Synthesis", Acc. Chem. Res. 38 (2005) 653-61.

[24] C. R. Strauss, "Applications of Microwaves for Environmental Benign Organic Chemistry", em J. Clark e D. Macquarrie (eds.), "Handbook of Green Chemistry \& Technology", Blackwell (2002), Cap17, p. 397-415.

[25] C. O. Kappe, "Controlled Microwave Heating in Modern Organic Synthesis", Angew. Chem. Int. Ed. 43(2004)6250-84.

[26]A. Hoz, A.Diaz-OrtizeA. Moreno, "Microwaves in Organic Synthesis - Thermal and Non-thermal Microwave Effects", Chem. Soc. Rev. 34 (2005) 164-78.

[27] M. Nuchter, B. Ondruschka, W. Bonrath e A. Gum, "Microwave Assisted Synthesis - A Critical Technology Overview", Green Chem. 6 (2004) 128-41.

[28] M. Nuchter, U.Muller, B. Ondruschka, A. Tied e W. Lautenschlager, "Microwave-Assisted Chemical Reactions", Chem. Eng. Technol. 26 (2003) 1207-16.

[29] M. J. Gronnow, R. J. White, J. H. Clark e D. J. Macquarrie, "Energy Efficiency in Chemical Reactions: A Comparative Study of Different Reaction Techniques", Org. Process Res. Dev. 9 (2005) 516-8.

[30] T. M. Barnard, N. E. Leadbeater, M. B. Boucher, L. M. Stencel e B. A. Wilhite, "Continuous-Flow Preparation of Biodiesel Using Microwave Heating", Energy Fuels 21 (2007) 1777-81.

[31] T. Razzaq e C. O. Kappe. "On the Energy Efficiency of Microwave-Assisted Organic Reactions", ChemSusChem 1 (2008) 123-32.

[32] T. N. Glanov e C. O. Kappe, "Microwave-Assisted Synthesis under Continuous-Flow Conditions", Macromol. Rapid Commun. 28 (2007) 395-410.

[33] J. M. Kremsner, A. Stadler e C. O. Kappe, "The Scale-up of Microwave-Assisted Organic Synthesis", Top. Curr. Chem. 266 (2006) 233-78.

[34] S. A. Miller, A. E. Landis e T. L. Theis, "Environmental Trade-offs of Biobased Production", Environ. Sc. Technol. 41 (2007) 5176-82.

[35] M. E. D. Oliveira, B. E. Vaughan e E. J. Rykiel Jr, "Ethanol as Fuel: Energy, Carbon Dioxide Balances and Ecological Footprint", BioScience 55 (2005) 593-602.

[36] A. A. S. C. Machado, "Métricas da Química Verde - A Produtividade Atómica", Química - Bol. S. P. Q. 107 (2007) 47-55. 
[37] P. Anastas, "Green Chemistry Design, Innovation, Solutions and a Cohesive System", Green Chem. Let. Rev. 1(2007)3-4.

[38] J. Reason, "Human Error", Cambridge University Press (1990), p. 8.

[39] C. Hall, P. Tharakan, J. Hallock, C. Cleveland e M Jefferson, "Hydrocar- bons and the Evolution of Human Culture", Nature 426 (2003) 318-22.

[40] N. Chambers, C. Simmons e M. Wackernagel, "Sharing Natures's Interests - Ecological Footprints as an Indicator of Sustainability", Earthscan (2000).

[41] M. Wackernagel e W. Rees, "Our Eco- logical Footprint - Reducing Human Impact on the Earth", New Society Publishers (1996), p. 7.

[42] C. Ponting, "A New Green History of the World - The Environment and the Collapse of Great Civilisations", Vintage (2007), p. 67-68.

\section{Actualidade Científica}

\section{O Cheiro do Cancro}

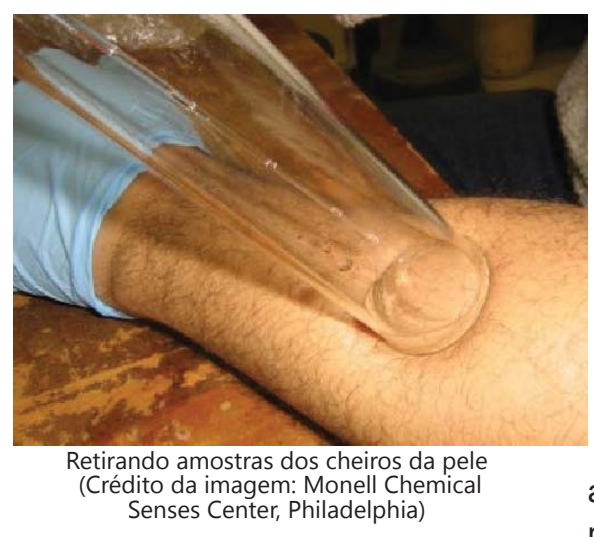

Terminou no dia 21 de Agosto em Filadélfia o $236^{\circ}$ Encontro da American Chemical Society, ACS, onde foram apresentados os trabalhos mais recentes da comunidade química norte-americana. Um dos trabalhos apresentados, «First detection of 'odor profile' for skin cancer may lead to rapid, non-invasive diagnostic test», poderá levar ao desenvolvimento a breve trecho de uma técnica de diagnóstico de cancro de pele absolutamente revolucionária.

Apenas nos Estados Unidos, são diagnosticados mais de um milhão de cancros de pele por ano. Os carcinomas espino-celulares e basocelulares são a forma mais comum de cancro da pele, normalmente não fatais: a maioria das mortes relacionadas com cancro de pele é devida a melanomas, que dão conta de cerca de 5\% dos casos diagnosticados.

As pessoas que se suspeita poderem desenvolver cancros de pele necessitam submeter sinais suspeitos a exames e biópsias frequentes de forma a que eventuais tumores possam ser detectados numa fase inicial. O trabalho de Michelle Gallagher, uma post-doc do MonellChemicalSenses Center, em
Filadélfia actualmente a trabalhar na Rohm \& Haas, poderá permitir o desenvolvimento de testes de diagnóstico simples e não invasivos.

Há muito que se suspeita que os tumores libertam um cheiro único graças a uma série de estudos que indicam que os cães podem cheirar melanomas e outros cancros. Por exemplo, Armand Cognetta, um dermatologista de Tallahassee, na Florida, treinou um cão para encontrar amostras de melanomas escondidas numa sala assim como detectar melanomas na pele de pacientes enquanto Carolyn Willis, do Amersham Hospital em Inglaterra, os utilizou para detectar cancro da bexiga.

«Os cães cheiravam qualquer coisa mas ninguém conseguiu descobrir exactamente o quê», referiu Michelle Gallagher que, sob orientação de George Preti, um químico do Monell Center, tentou descobrir quais os compostos químicos em causa.

Para isso, a equipa trabalhou com 11 doentes aos quais tinham sido diagnosticados carcinomas basocelulares e com um grupo de controle escoIhido de acordo com a idade, género e etnicidade dos pacientes. Ambos os grupos foram «limpos» de odores de fontes externas com uma semana de lavagem com produtos sem aroma e roupa fornecida pelos cientistas.

Depois da limpeza, as amostras de cheiro foram recolhidas com o auxílio de um funil dotado de um filtro absorvente colocado sobre a pele dos voluntários durante 30 minutos. A pele foi ainda lavada com uma solução alcoólica para recolher compostos não voláteis.

A equipa detectou quase 100 compostos químicos diferentes emanados pela pele usando técnicas de cromatografia em fase gasosa e espectrometria de massa.

Os perfis químicos da pele saudável e cancerosa são diferentes quer no tipo quer nas concentrações de VOCs (volatile organic compounds, compostos orgânicos voláteis).

«Descobrimos dois compostos químicos em particular cujo perfil era significativamente diferente quando se comparava um paciente com cancro e um saudável» explicou Gallagher, sublinhando que «estão presentes os mesmos compostos químicos em ambos os casos, mas junto aos tumores as quantidades de certas substâncias químicas aumentam, enquanto a presença de outras diminui, em comparação com o perfil das pessoas saudáveis».

Os autores não indicaram quais as substâncias químicas em causa uma vez que pretendem procurar outros marcadores, nomeadamente associados também ao carcinoma espinocelular e ao melanoma, e patentear a sua descoberta. Se forem bem sucedidos, os narizes electrónicos em desenvolvimento poderão então ser utilizados em testes de diagnóstico. 